\title{
Investigation on the influence of the initial RDX crystal size on the performance of shaped charge warheads
}

\author{
F. Majiet ${ }^{\mathrm{a},{ }^{*}}$, F.J. Mostert ${ }^{\mathrm{b}}$ \\ ${ }^{a}$ Rheinmetall Denel Munition, Somerset West, South Africa \\ ${ }^{\mathrm{b}}$ Centre for Scientific \& Industrial Research, Pretoria, South Africa
}

\section{A R T I C L E I N F O}

\section{Article history:}

Received 26 February 2019

Received in revised form

8 June 2019

Accepted 15 July 2019

Available online 16 July 2019

\begin{abstract}
A B S T R A C T
Copper lined wave shaped shaped charges of particular design and liner metallurgy were used to investigate the effect of explosive crystal size on the resultant shaped charge jet parameters. Composition A3 with RDX of three different average crystal sizes, i.e. $30 \mu \mathrm{m}, 100 \mu \mathrm{m}$ and $300 \mu \mathrm{m}$ were used in the investigation. All other parameters in the charge were kept constant and in particular, care was given to obtain consistent dimensional quality and liner microstructure, in order to prohibit the variation of other parameters. Specific flash-X-ray diagnostics were used in field tests to obtain the jet parameters from multiple firings of similar charges. It is found that the varying crystal size of the RDX has a marginal influence in the total jet length of the jets. However, it is also found that there is less variation between firings in the jet parameters for jets from the charges loaded with the crystal size of $100 \mu \mathrm{m}$.

(C) 2019 Production and hosting by Elsevier B.V. on behalf of China Ordnance Society. This is an open access article under the CC BY-NC-ND license (http://creativecommons.org/licenses/by-nc-nd/4.0/).
\end{abstract}

\section{Introduction}

Warhead designers are continually in pursuit of improving the performance of their products. For decades, shaped charge designers have focused on liner material [1-5], the microstructure of the liner material, initiation systems and different explosive materials. Few researchers have quantified the influence of the explosive microstructure or the initial energetic material crystal size on the performance of shaped charges. Generally, a qualified explosive is used to quantify various parameters of shaped charge jets. This paper aims at providing experimental data demonstrating the influence of the explosive crystal size on the cumulative lengths generated in precision shaped charge jets.

Rheinmetall Denel Munition is in the fortunate position of manufacturing small batches of explosives within pilot plants whilst pressing explosives and manufacturing liners all at one site. This provided the opportunity to conduct this investigation with full control of all the relevant manufacturing parameters.

An $80 \mathrm{~mm}$ diameter concept warhead design was selected containing a $60^{\circ}$ copper cone with an average liner grain size of $30 \mu \mathrm{m}$ with a variation of $10 \mu \mathrm{m}$, Comp A3 - RDX91:WAX9 main

\footnotetext{
* Corresponding author.

E-mail address: fakhree.majiet@rheinmetall-denelmunition.com (F. Majiet).

Peer review under responsibility of China Ordnance Society
}

and relay charge with a combined mass of approximately $580 \mathrm{~g}$, wave shaper for peripheral initiation, as shown in Fig. 1. No housing/confinement was used for this evaluation.

The trending motion of the explosive community has moved from TNT based explosives onto plastic bonded explosives and now even more modern binder materials for more insensitive explosives. Optimizing an explosive material for the improvement of its sensitivity/insensitivity involves an optimization process in terms of explosive crystal size. Some formulations make use of monomodal, bi-modal and even tri-modal explosive mixtures. A few decades ago, shaped charges were typically cast with a mixture of TNT and other explosives. Early attempts were made to measure the roughness of the detonation front resulting from inhomogeneity's of the explosive and the detonation front. The question was raised if this roughness has an impact on the performance of a shaped charge jet (SCJ). However, experiments were difficult to perform due to the many other parameters in the charge that could vary and results were either inconclusive, or showed that the influence was only marginal [6]. This question re-emerged when the classical cast, or pressed-cast, TNT based explosives were replaced by plastic bonded explosives (PBX) to make the charges more insensitive [7]. While the TNT in previous compositions (effectively a castable binder the explosive mixture) was detonable and the detonation front could propagate with closely similar velocity in the explosive and in the 'binder', this is not the case with the inert plastic binders. Consequently, the use of PBX should increase the roughness of the 


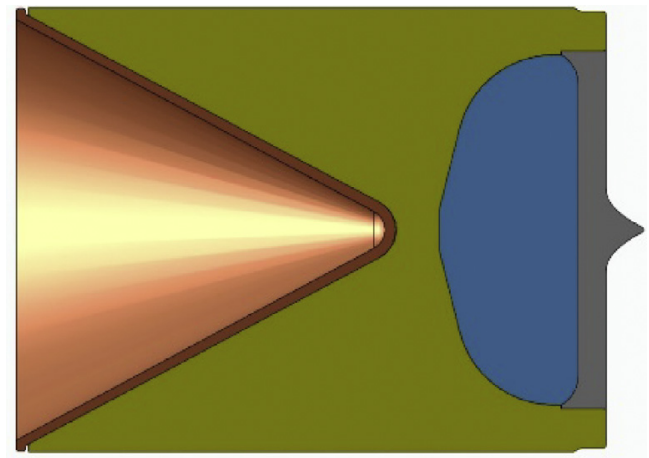

Fig. 1. Concept warhead design for evaluation.

detonation front [8].

The characterisation of the crystal structure in the explosive is well established process and has been used as a tool for correlating parameters such as explosive sensitivity, efficiency of different binders [9], the formation of hotspots with in a granulated pressed PBX [5,6], evaluation of pressing quality $[7,8]$ and evaluating fractal

Table 1

Various lots of Comp A3 manufactured with different RDX grades/crystal sizes.

\begin{tabular}{llll}
\hline RDX Grading & Coarse & Medium & Fine \\
\hline Lot & 003 & 005 & 006 \\
RDX Name & 107 & 105 & 104 \\
RDX Grain Size $/ \mu \mathrm{m}$ & $300-400$ & 100 & $20-30$ \\
\hline
\end{tabular}

networks of intergranular voids [14].

Crystal sizes of $30 \mu \mathrm{m}, 100 \mu \mathrm{m}$ and $300 \mu \mathrm{m}$ were selected for this investigation. The fine crystal size was selected to be comparable to the average grain size of the copper liners. The larger crystals were selected three and ten times larger to ensure good variation in the three the explosive batches.

This particular project made use of Comp A3: RDX 91\% - Wax 9\%. Three batches of RDX were manufactured with different crystal sizes at RDM's pilot plants. These three batches of explosives were placed behind OFHC copper liners with a fixed average grain size of $30 \mu \mathrm{m}$. These liners form part of another investigation, where the emphasis is on strict control of the microstructure and dimensional consistency. The investigation of this paper focusses on quantifying the effects of RDX particle size on the breakup behaviour of the shaped charge jets.

\section{Explosive analysis}

A detailed analysis of the explosive granular product is shown from RDX selection, to wax coating and then after pressing.

Three batches of the Comp A3 (RDX/WAX 91/9, $\rho=1.63 \mathrm{~g} / \mathrm{cm}^{3}$ ) with the different RDX particle sizes were manufactured within a pilot plant as shown in Table 1. SEM images of the respective RDX types are presented in Fig. 2. Images of the three different Comp A3 batches are shown in Fig. 3. By visual inspection it was already noted that the granular material produced after coating with wax, showed particle size differentiation. Molding powder granules of PBX were prepared using the standard slurry coating process [15-17]. Gravimetric analysis were conducted on the three Comp A3 batches to ensure the RDX/WAX ratio was obtained. The results
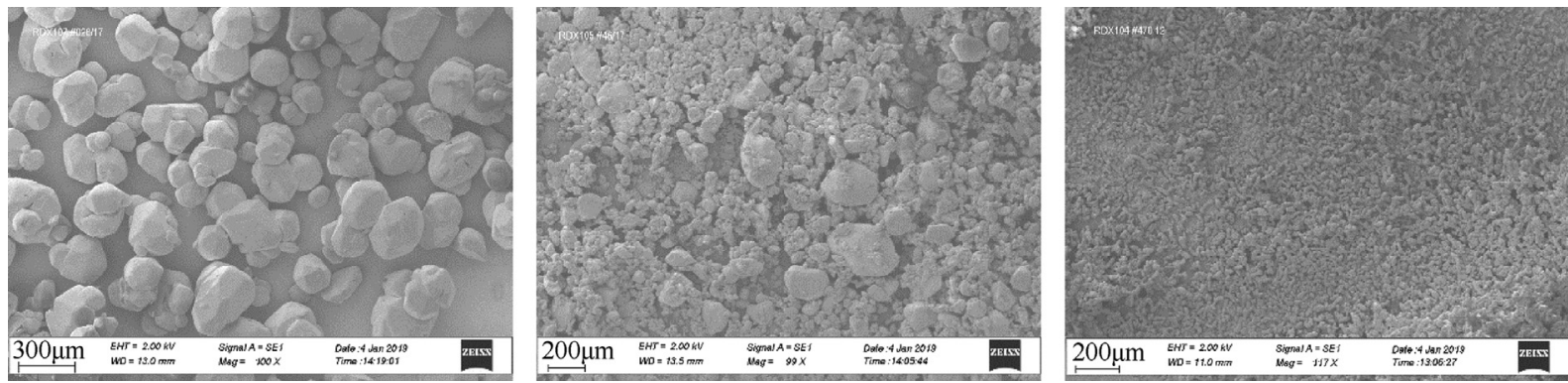

Fig. 2. Scanning electron microscope images of RDX 107, 105 \& 104 respectively.

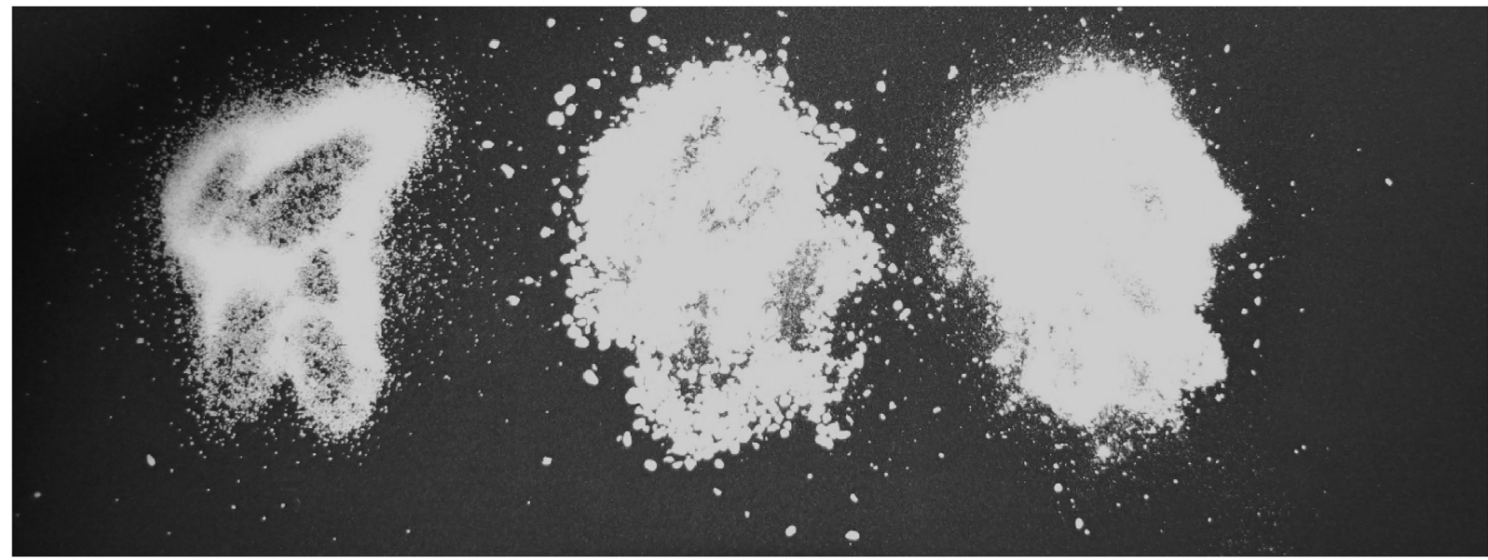

Lot 3

Lot 5

Lot 6

Fig. 3. Three lots of granular Comp A3. 
Table 2

Comp A3 - RDX-WAX ratio analysis.

\begin{tabular}{llll}
\hline Characteristics & Lot 003 & Lot 005 & Lot 006 \\
\hline RDX/\% & 91.5 & 90.3 & 90.5 \\
Wax/\% & 8.5 & 9.7 & 9.5 \\
\hline
\end{tabular}

are presented in Table 2, and revealed all three were within specification with a variation of less than $1 \%$.

\section{Pressing analysis}

All three batches of Comp A3 were used to conduct a pressing analysis. Charges were pressed at room temperature and an elevated temperature of $70^{\circ} \mathrm{C}$ at $100 \mathrm{MPa}, 150 \mathrm{MPa}$ and $200 \mathrm{MPa}$ effective pressure. The size of the charges pressed for the Comp A3 pressing analysis was $25 \mathrm{~mm}$ in diameter and $25 \mathrm{~mm}$ long. A summary of the pressing analysis presented in Fig. 4. The densities were calculated by measured the diameters and lengths of each explosive charge.

The pressing analysis shows an increase in density at $21^{\circ} \mathrm{C}$ from 94.1\% TMD up to 95.67\% TMD with an increase in effective pressure from $100 \mathrm{MPa}$ to $200 \mathrm{MPa}$ for batch 6 . The densities measured for lots 3 to 5 were uniform at room temperature and at elevated temperatures. The press was heated to $70^{\circ} \mathrm{C}$ and new charges were pressed at similar pressures. A more uniform density distribution was measured across a variety of pressures for batch 6 when conditioned at $70^{\circ} \mathrm{C}$. This can be explained due to the binder softening at high temperatures. The density of all charges across batches at elevated temperature was within $0.025 \mathrm{~g} / \mathrm{cm}^{3}$ from $100 \mathrm{MPa}$ to $200 \mathrm{MPa}$ effective pressure.

The densities for the consolidated charges when heated to $70^{\circ} \mathrm{C}$ are shown in Fig. 5. Based on the data a single pressure of $150 \mathrm{MPa}$ was selected to press the larger diameter charges. The difference in densities measured for the respective charges at $150 \mathrm{MPa}$ were $0.013 \mathrm{~g} / \mathrm{cm}^{3}$. This change in density should not influence the performance of the shaped charge jets.

The final charges, $85 \mathrm{~mm}$ diameter, manufactured were pressed at $150 \mathrm{MPa}$ at $70^{\circ} \mathrm{C}$. The light micrographs shows the difference

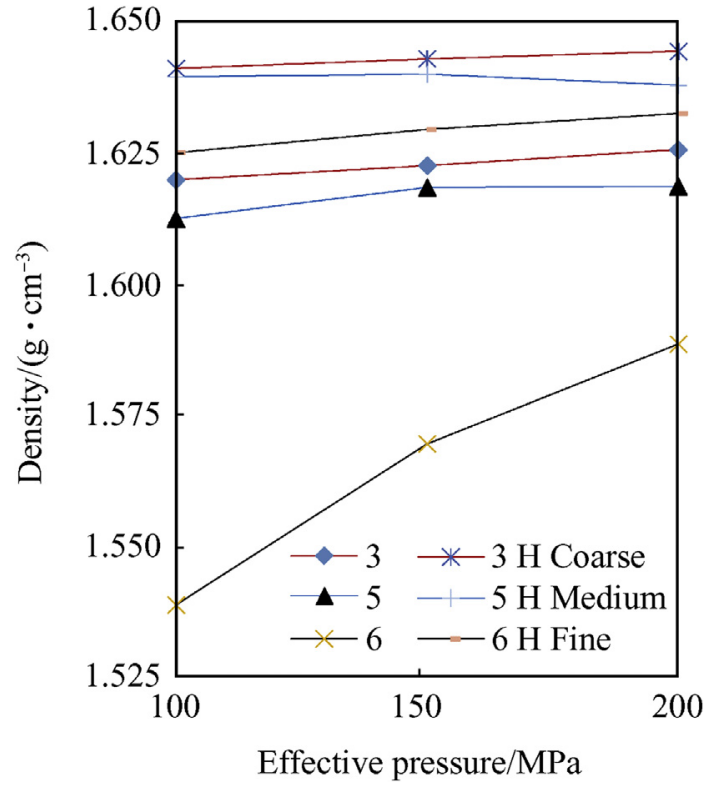

Fig. 4. Density report for consolidated charges.

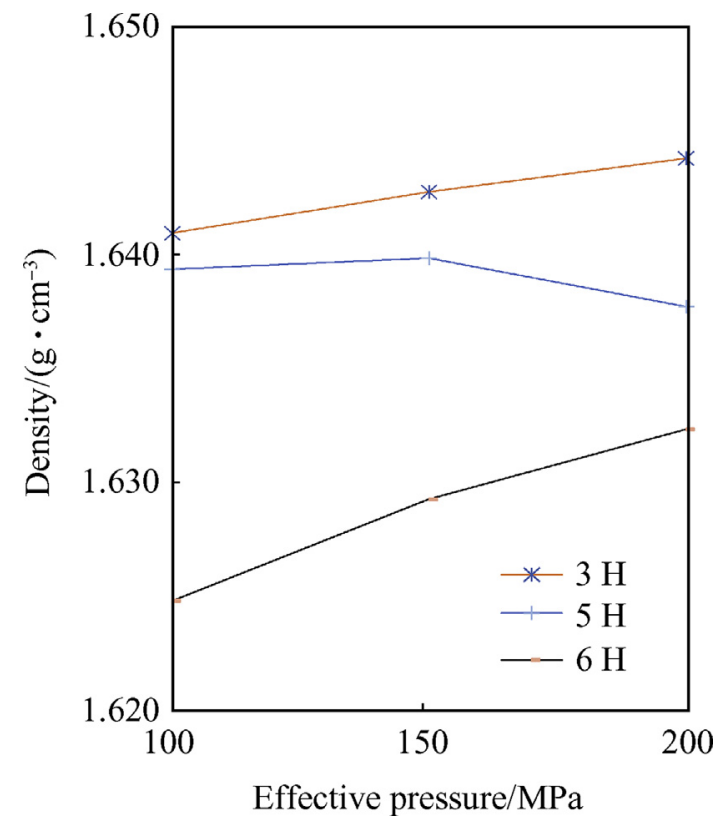

Fig. 5. Density report for the consolidated charges heated to $70^{\circ} \mathrm{C}$ only.

between the fine and coarse pressed charges shown in Fig. 6. An image of the machined Comp A3 is presented in Fig. 7.

\section{Warhead manufacture}

The $85 \mathrm{~mm}$ pressed Comp A3 charges were machined down to a
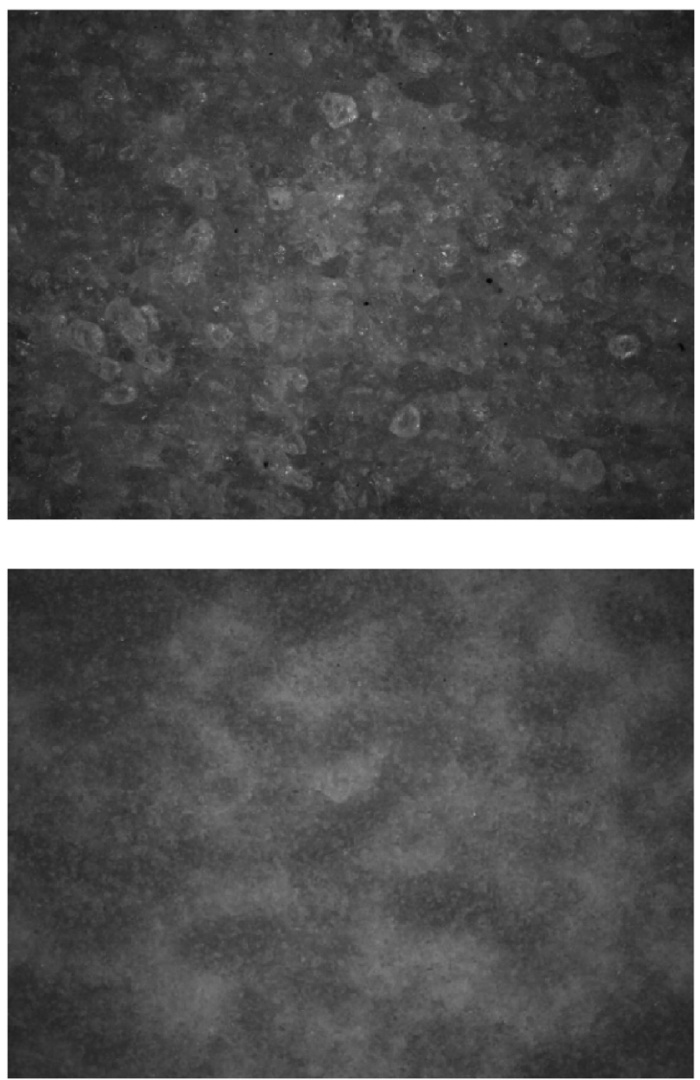

Fig. 6. Light microscopy of the pressed Comp A3, coarse (top) and fine (bottom) 


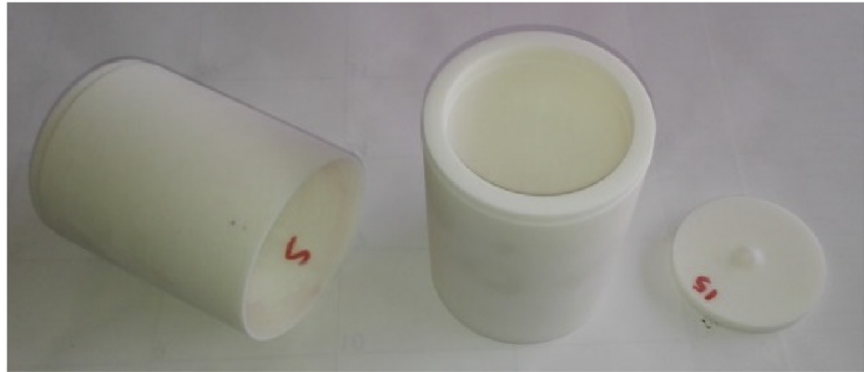

Fig. 7. Machined Comp A3 charges.

final warhead calibre of $80 \mathrm{~mm}$. An image of the machined charges are shown in Fig. 7. A foam wave shaper was used and a copper liner with thickness of $1.7 \mathrm{~mm}$.

\section{Flash X-ray analysis}

Flash X-ray analysis is the general accepted diagnostic tool used to characterise shaped charge jets [18-21]. A $450 \mathrm{kV}$ double flash Xray system was used for the firings. An image of the test setup is presented in Fig. 8. The $450 \mathrm{kV}$ system had a beam wide enough to capture the particulated shaped charge jet from tip to slug. Position markers were placed in each firing to ensure accurate allocation to the distance travelled of each particle. The first flash time ensured the jet tip captured at a large standoff to ensure particulation down to $4 \mathrm{~mm} / \mu \mathrm{s}$. The second flash time ensured jet particulation down to the jet tail/slug. Examples of the flash X-ray radiographs presented in Fig. 9 (fine RDX) and Fig. 10 (coarse), respectively. The radiographs are analysed with a locally developed code called

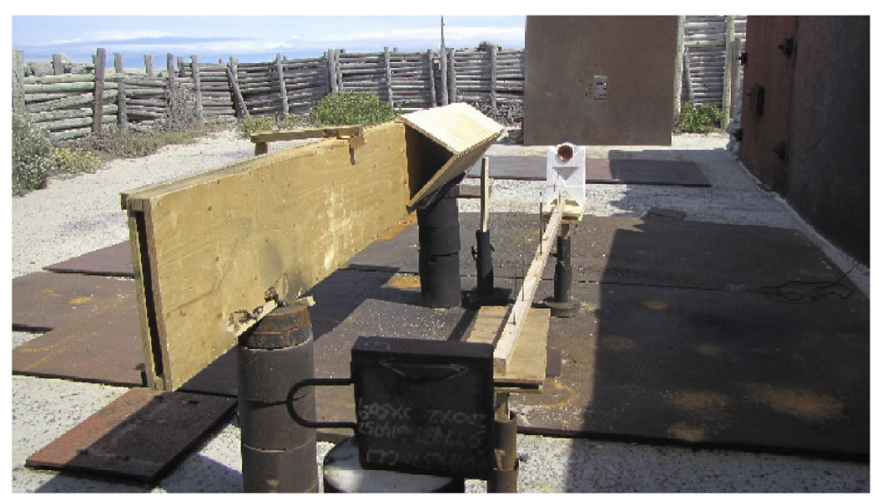

Fig. 8. Flash X-ray setup.
JETPMI. The program is a Matlab based image detection software, which write out the most important shaped charge jet properties as output. For the purpose of this paper, reporting of only the jet cumulative lengths is required. A demonstration of the digitised particles shown in Fig. 11. The cumulative lengths of the shaped charge jets presented in Fig. 12. The length of each particle was measured with a matching particle velocity. The cumulative length per velocity segment is the sum of the particles measured up to that particle. The graph on the left presents the cumulative length of the shaped charge jet from tip down to approximately $4 \mathrm{~mm} / \mu \mathrm{s}$. The graph on the right zooms into the $5 \mathrm{~mm} / \mu$ s regime outlining the variation of the duplicate firings. The average breakup times and average length/diameter ratios for particles of the shaped charge jets are presented in Fig. 13.

\section{Analysis and discussion}

The cumulated length of the jet can be regarded as one of the most important parameters for the SCJ jet performance [5,10-13]. The influence of the explosive crystal size distribution on this parameter is thus of particular importance. The tip velocity measured for each firing was $8.6 \pm 0.1 \mathrm{~mm} / \mu \mathrm{s}$. The tip velocities of each jet was measured by double flash X-ray radiographs only. Fig. 12 shows the results for duplicate firings for the cumulative length per jet velocity interval. The graphs depicted show marginal influence of the explosive grain size distribution on the average cumulative jet length of the combined firings. However, there are differences in the variation of the individual jet length of similar firings. Explosive lot 6 (black) had a variation of $20 \%$ in cumulative length at $5000 \mathrm{~mm} / \mu \mathrm{s}$. Explosive lot 3 (red) showed a variation of less than $10 \%$ in cumulative length at $5 \mathrm{~mm} / \mu \mathrm{s}$. Explosive lot 5 (blue) showed a variation of less than $5 \%$ in cumulative length at $5 \mathrm{~mm} / \mu \mathrm{s}$. The data suggests that the explosive microstructure has little influence on the overall shaped charge jet cumulative length. The data rather indicate that an RDX crystal size of $100 \mu \mathrm{m}$ produces more consistent jets; an initial explosive crystal size of $300-400 \mu \mathrm{m}$ being too coarse and $20-30 \mu \mathrm{m}$ being too fine. The physical and chemical explanation for this observation is the topic of a continued investigation. The number of particles from jet tip down to $4 \mathrm{~mm} / \mu$ s were $45 \pm 2$ for the six firing with an average velocity difference of $100 \pm 15 \mathrm{~m} / \mathrm{s}$ between particles. The average breakup times presented in Fig. 13 (left), shows an average breakup time of $80 \mu \mathrm{s}$ at the tip and approximately $280 \mu \mathrm{s}$ at $3 \mathrm{~mm} / \mu \mathrm{s}$; the spread of data also verifies the consistency of the RDX crystal size of $100 \mu \mathrm{m}$ and the variation in breakup times of the fine and coarse RDX crystals throughout the jet. The break up times were calculated by measuring the inter particle spaces and the velocity difference between those particles. The time was traced back to the point these particles meet. This time is considered the breakup time. The
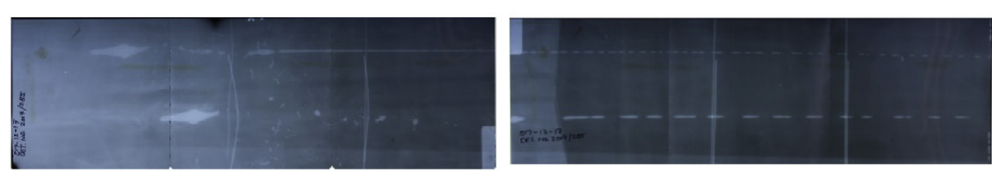

Fig. 9. Lot 6 (fine)
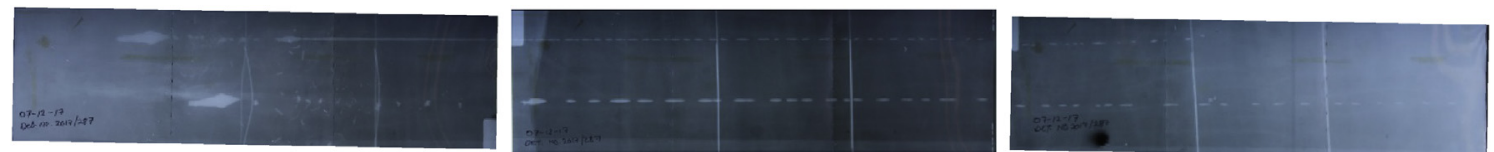

Fig. 10. Lot 3 (coarse). 

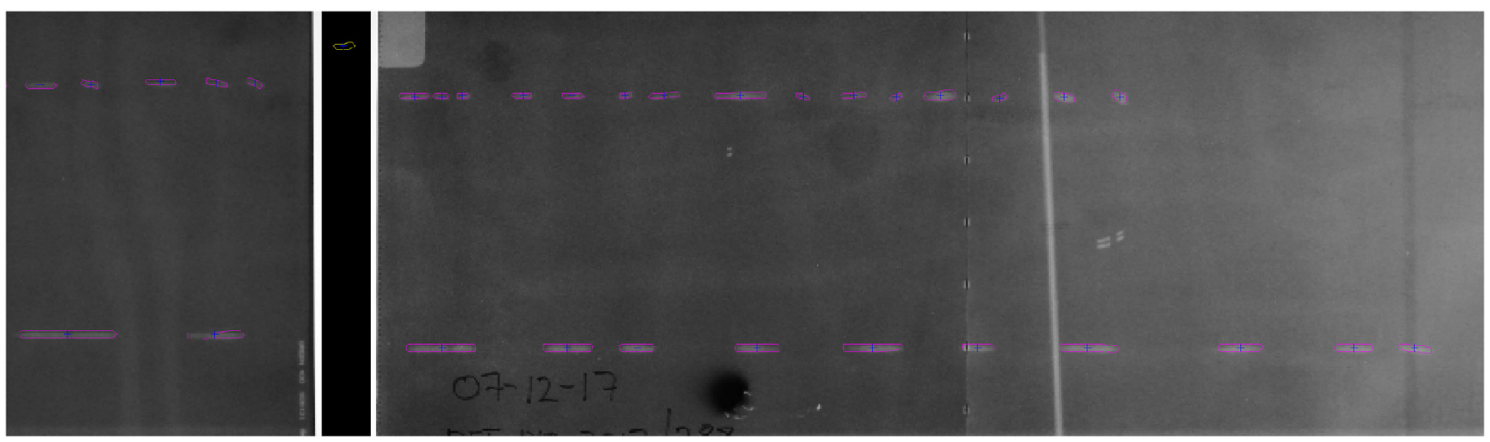

Fig. 11. Image Detection Software used for flash X-ray analysis, JETPMI.
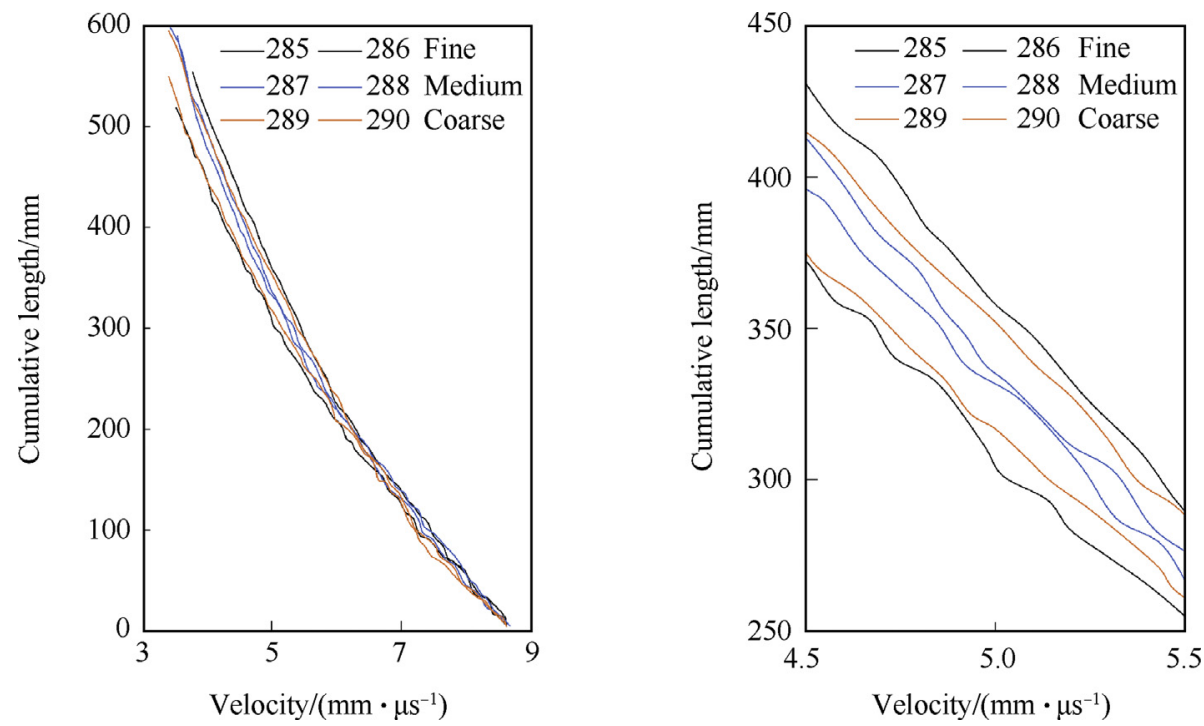

Fig. 12. Flash X-Ray Analysis - Cumulative length of shaped charge jet.
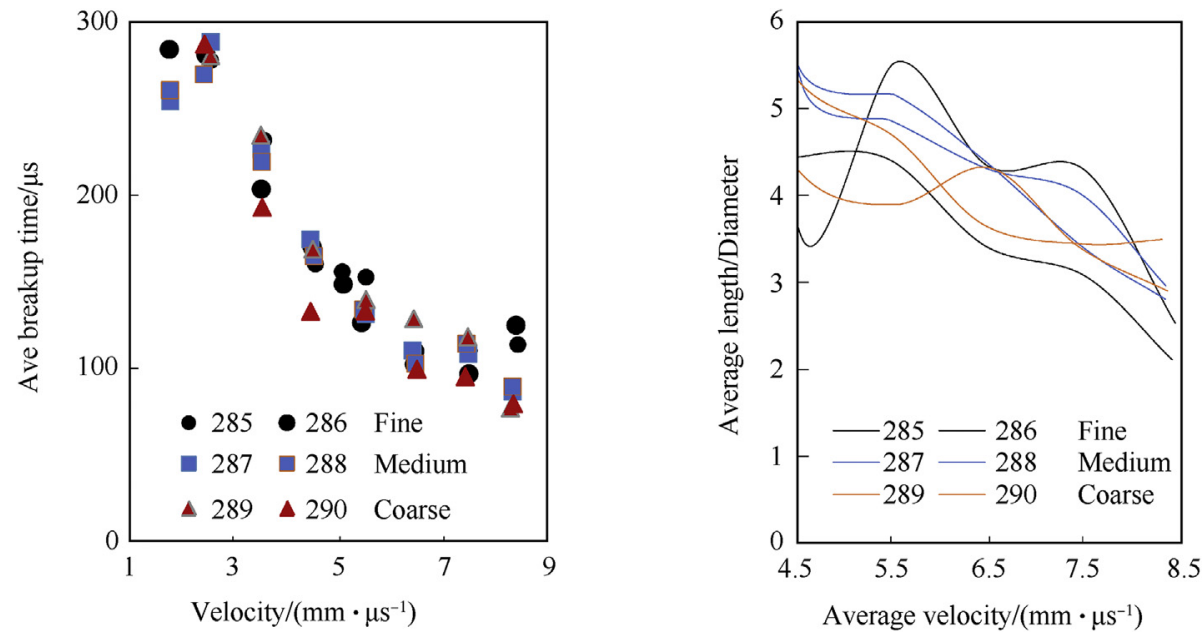

Fig. 13. Flash X-Ray Analysis - Average breakup times (left) and average L/D of particles (right) of shaped charge jets.

average breakup time is the breakup time of all particles in a $1 \mathrm{~mm} /$ $\mu$ s velocity segment. The breakup times are averaged for particles in between $6 \mathrm{~km} / \mathrm{s}$ and $7 \mathrm{~km} / \mathrm{s}$ and so on. The L/D ratio presented in Fig. 13 right refers to the length to diameter ratio of each particle digitised for test. The average $\mathrm{L} / \mathrm{D}$ ratios of the shaped charge jet particles are presented in Fig. 13 (right). The average L/D were also calculated for each $1 \mathrm{~mm} / \mu$ s velocity segment. The graph shows an average $\mathrm{L} / \mathrm{D}$ of 2.5 at the jet tip increasing up to 5.5 at $4.5 \mathrm{~mm} / \mu \mathrm{s}$. The $\mathrm{L} / \mathrm{D}$ ratios also confirmed the consistency for the medium sized RDX crystals. 


\section{Conclusion}

Three batches of Comp A3 (RDX:WAX-91:9) were manufactured with different initial RDX crystal sizes. A range of $30 \mu \mathrm{m}, 100 \mu \mathrm{m}$ and $300 \mu \mathrm{m}$ was selected for the evaluation. Chemical analysis showed all three batches conformed to the 91:9 RDX:WAX ratio within $1 \%$ tolerance. The pressing analysis showed all three press charge densities ( $\rho=1.63 \mathrm{~g} / \mathrm{cc}$ ) to be comparable within $0.25 \% \mathrm{~g} /$ $\mathrm{cm}^{3}$. Precision shaped charge warheads were manufactured with copper liners with an average grain size of $30 \mu \mathrm{m}$. Six flash X-ray firings were conducted to quantify the influence of the RDX crystal size on the cumulative length of jets produced. The data showed a rather equal trend in terms of break up times and cumulative length for the average of similar firings. The variation of these parameters between the similar firings, however, differed. The conclusion drawn from the data generated is rather that an optimum RDX crystal size exist for such composition that will produce more consistent jet parameters. In the case of this investigation, the $100 \mu \mathrm{m}$ RDX-105 produced more consistent shaped charge jets over and above that of the RDX $104(20-30 \mu \mathrm{m})$ and RDX 107 $(300-400 \mu \mathrm{m})$ mixtures.

\section{Acknowledgement}

The authors would like to thank all RDM team members for their support of this work.

\section{References}

[1] Gurevitch AC, et al. Characterization and comparison of microstructures in the shaped-charge regime: copper and tantalum. Mater Char 1993;30(3):201-16.

[2] Guo W, Li SK, Wang FC, Wang M. Dynamic recrystallization of tungsten in a shaped charge liner. Scr Mater 2009;60(5):329-32.

[3] Murr LE, Niou C-S, Garcia EP, Ferreyra E, Rivas TJM, Sanchez JC. Comparison of jetting-related microstructures associated with hypervelocity impact crater formation in copper targets and copper shaped charges. Mater Sci Eng A 1997;222(2):118-32.
[4] Tian WH, Fan AL, Gao HY, Luo J, Wang Z. Comparison of microstructures in electroformed copper liners of shaped charges before and after plastic deformation at different strain rates. Mater Sci Eng A 2003;350(1-2):160-7.

[5] Shih HK, Murr LE, Niou CS, Zernow L. Dynamic recrystallization in a tantalum shaped charge. Scr Metall Mater 1993;29(10):1291-6.

[6] Chanteret PY, Bequve A, Kerdraon MA. A study of the influence of HE grain sizes on the shaped charge jet fragmentation. In: Proc. 13th int. Symp. On ballistics; 1992.

[7] I. Plaksin, "Effects of meso-scale perturbations in the detonation reaction zone on shaped charge liner response“, Proc. 28th int. Symp. On ballistics, Atlanta, GA,.".

[8] W. Arnold, Effect of insensitive HE on shaped charge jets Werner Arnold, Thomas Hartmann 2, Ernst Rottenkolber 2.

[9] Skidmore CB, Phillips DS, Howe PM, Mang JT, Romero JA. The evolution of microstructural changes in pressed HMX explosives. In: Eleventh international detonation symposium; 1998. p. 556-64.

[10] Barua A, Zhou M. A Lagrangian framework for analyzing microstructural level response of polymer-bonded explosives. Model Simul Mater Sci Eng 2011;19(5):055001.

[11] Belmas R, Plotard J-P. Physical origin of hot spots in pressed explosive compositions. J Phys IV 1995;5(C4):C4-61-4-87.

[12] Peterson PD, Fletcher MA, Roemer EL. Influence of pressing intensity on the microstructure of PBX 9501. Energ Mater 2003;21(4):247-60.

[13] Cambronero LEG, Gordo E, Torralba JM, Ruiz-Prieto JM. Comparative study of high speed steels obtained through explosive compaction and hot isostatic pressing. Mater Sci Eng A 1996;207(1):36-45.

[14] Mang JT, Hjelm RP. Fractal networks of inter-granular voids in pressed TATB. Propellants, Explos Pyrotech 2013;38(6):831-40.

[15] Gardner AE. Process for desensitizing solid explosive particles by coating with wax. Google Patents; 1970.

[16] Han PS, Jordan D. Coating process for plastic bonded explosive. Google Patents; 2002.

[17] Ringbloom VD. Process for coating crystalline explosives with polyethylene wax. Google Patents; 1982.

[18] Held M. Determination of the material quality of copper shaped charge liners. Propellants, Explos Pyrotech 1985;10(5):125-8.

[19] Held M. The orthogonal synchro-streak technique as a diagnostic tool, particularly for shaped charge jets. Propellants, Explos Pyrotech 1986;11(6): 170-5.

[20] Bourne B, Cowan KG, Curtis JP. Shaped charge warheads containing low melt energy metal liners. In: Proc. 19th int. Symp. Ballistics, Switzerland; 2001. p. 583-9.

[21] Petit J, Jeanclaude V, Fressengeas C. Breakup of Copper shaped-charge jets: experiment, numerical simulations, and analytical modeling. J Appl Phys 2005;98(12):123521. 